SHAILENDRA CHAWLA ASHOK JAISWAL and

B K. SHRIVASTVA

\title{
Design of remnant pillar in mechanized depillaring using continuous miner
}

Ribs and snooks are the critical natural support at the goaf edge in the mechanized depillaring operation of the bord and pillar mining system. The pillar extraction has been carried out by taking the slices and leaving ribs and snooks during the depillaring operation. Remnants are the remaining portion of the extracted pillar. The depillaring operation leads to an unsupported roof, and the immediate unsupported roof imposes its weight on the pillar (remnant) under extraction. The remnant's purpose is to provide a necessary reaction to the overhang to restrict roof failure until the pillar's final slice. The remnant's stability during depillaring operation has been accessed in the study using three-dimensional numerical simulations. A scheme has also been proposed in the study to evaluate the factor of safety (FOS*) of the remnant pillar in the residual phase at different stages of slicing operation. A case of an Indian coal mine using the fish-bone method has been chosen for the study. A typical depillaring stage has been selected for the extraction of the pillar using the fish-bone method. The numerical simulation of the considered panel provides the vertical stress and yielding profile on the pillars at different stages of depillaring. The simulation results show the influence zone up to one pillar from the goaf edge. The immediate intact pillar shows considerable yielding of about $60 \%$ of the pillar area. The remnants have completely yielded during the slicing operation but provide a reaction to the immediate strata. The remnant should provide the reaction to the immediate roof till taking the final slice from the pillar. The remnant's FOS* is calculated by taking the ratio of reaction offered by the remnant (numerical simulations) and the weight of the overhang (estimation). The area's borehole section shows two layers of medium to coarse-grained sandstone as an immediate stratum. The weight of the immediate strata has been estimated in the study considering the immediate strata's thickness. Two different scenarios of immediate strata thickness (i.e., 4.75 $m$ and $9 \mathrm{~m}$ ) have been considered in the study to evaluate

Blind peer reviews carried out

Messrs. Shailendra Chawla, Research Scholar, Department of Mining Engineering, IIT (BHU), Ashok Jaiswal, Associate Professor, Deptt. of Mining Engineering, IIT (BHU) and B. K. Shrivastva, Professor, Department of Mining Engineering, IIT (BHU), Varanasi, India the remnant's FOS at different depillaring stages.

Keyword: Remnant, ribs/snooks, fish-bone pattern, continuous miner, mechanized depillaring, numerical simulation.

\subsection{Introduction}

卫 The underground coal mines mostly prefer the bord and pillar mining system in India. The growing coal demand requires the mechanized depillaring to extract the coal from underground at a faster rate. A continuous miner (CM) is a suitable machine for mechanized depillaring operations in bord and pillar workings. In India, the bord and pillar panel developed by conventional mining methods (drill and blast) also adopt the CM technology during the depillaring operation. Many underground coal mines like Churcha, SECL; Pinoura, SECL; Tandsi, WCL; VK-7, SCCL; GDK-11, SCCL have adopted the mechanized depillaring practice in already developed panels. The pillars and galleries in the bord and pillar mining system are designed as per the coal mine regulations (CMR, 2017). The mechanized depillaring operation using $\mathrm{CM}$ demands more comprehensive galleries of about $5.0 \mathrm{~m}-6.5 \mathrm{~m}$ and an extraction height of more than $3.5 \mathrm{~m}$ (up to $5.0 \mathrm{~m}$ ). The widening and heightening of the galleries reduce the pillars' width-to-height ratio, leading to decreased FOS. The depillaring operation may cause strata issues like side spalling, roof instability, floor heaving, overriding depending upon the geo-mining conditions. Some researchers have studied strata control issues in Indian coal mines (Mandal P K et al., 2004; Singh R et al., 2011; Singh S $\mathrm{K}$ et al., 2017).

The present study focuses on the remnant's stability during the depillaring operation, as instability of the remnant may induce the overriding situation. Roof bolts are the only supporting element at the goaf edge during mechanized depillaring, unlike conventional mining, where cogs and props provide additional support to the immediate roof in addition to the ribs/snook. The remnant pillar's stability is essential in the absence of props and cogs, and the design of the remnant is a critical aspect in safe workings in mechanized depillaring operations. The study presents a three-dimensional numerical simulation scheme to design the remnant pillar based on the FOS. 


\subsection{Mechanized depillaring operation}

Depillaring operation exposes a large area of overlying strata and results in high induced stress on the nearby intact coal pillars. The coal pillar's extraction pattern during mechanized depillaring using CM is decided based on its FOS. There are various pillar extraction patterns, like split and fender, fishbone, and modified navid. The split and fender method is generally being adopted for pillar having a higher FOS. If the FOS of the pillar is less than 1.5, then splitting action further reduces the FOS of the fenders, which is not advisable. Hence, the fish-bone method is the preferred method of extraction for the pillars having a FOS less than 1.5. The study selects a typical bord and pillar case with smaller pillars adopting a fish-bone extraction pattern to propose the simulation scheme.

Fig.1a shows the extraction pattern using the fish-bone method highlighting the focus pillar. Fig.1b shows the slices' representative dimension of the remnant pillar after complete extraction, and Fig.1c shows the extraction sequence. Slice 1a and slice $2 \mathrm{a}$ of the working pillar have already been extracted during the previous pillar extraction. The sequence of extraction in the fish-bone pattern was such that the 'slice $1 \mathrm{a}$ ' and 'slice $1 \mathrm{~b}$ ' is taken from the nearby intact pillar after taking 'slice 1' and 'slice 2' respectively from the working
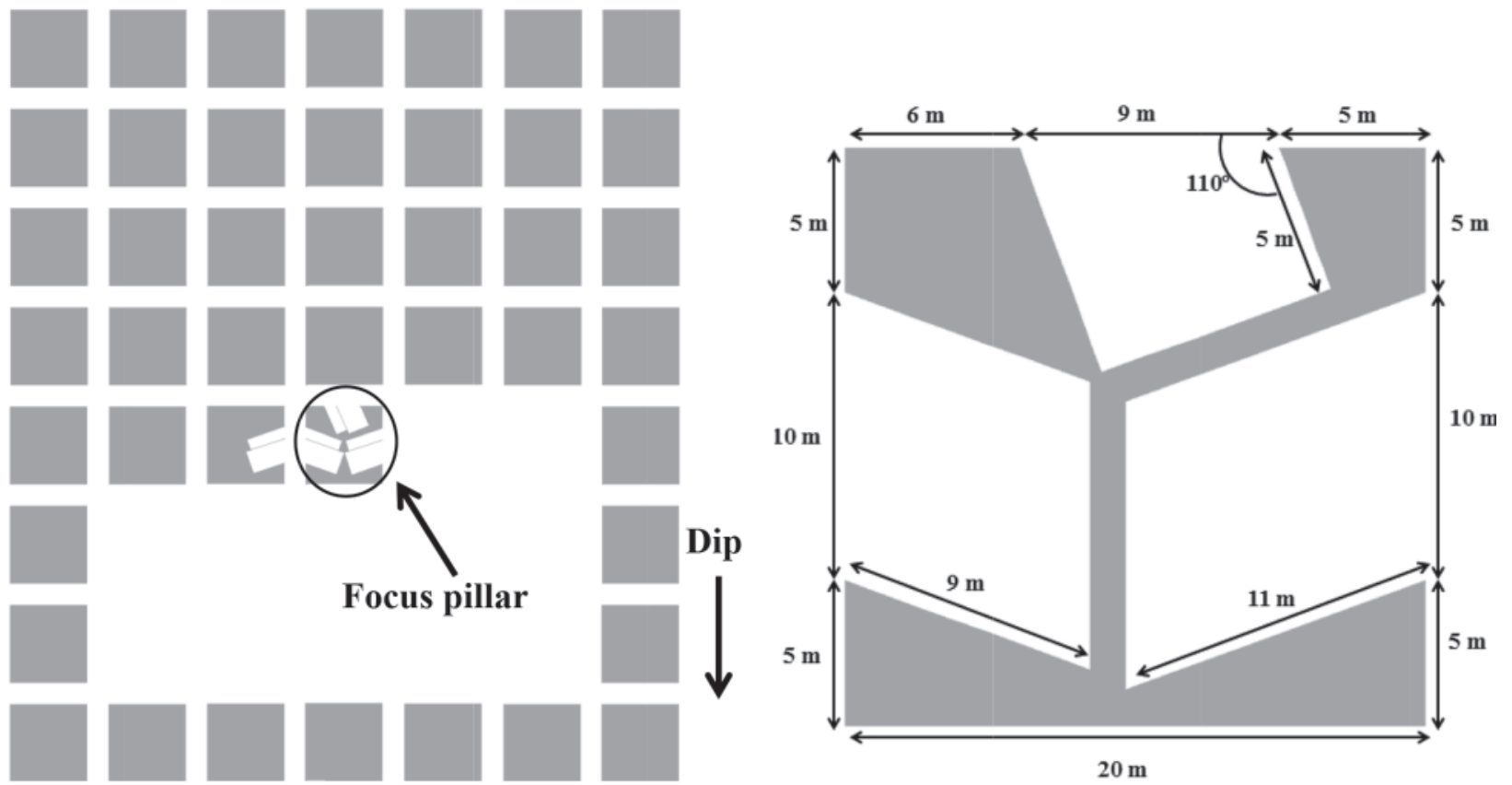

(a) Depillaring scheme

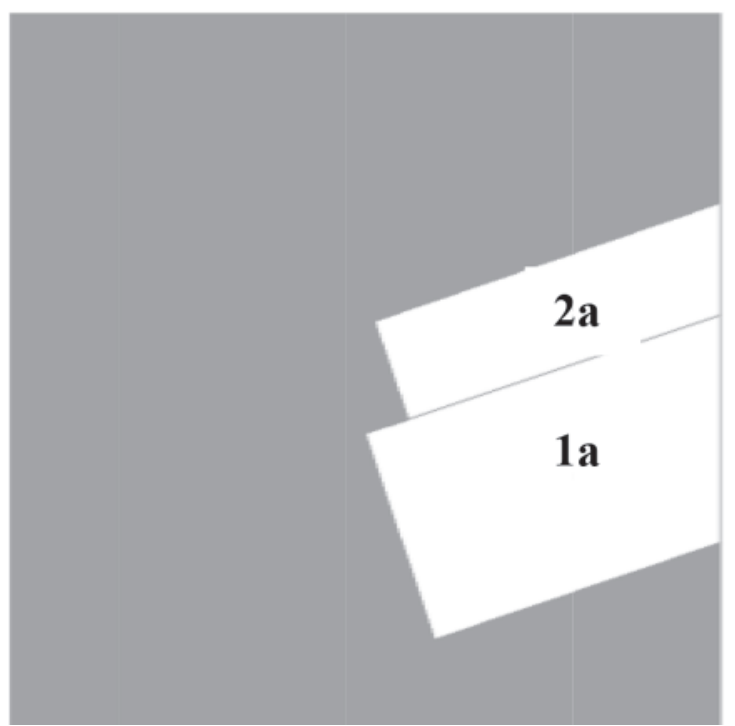

(b) Representative dimension of the remnant pillar

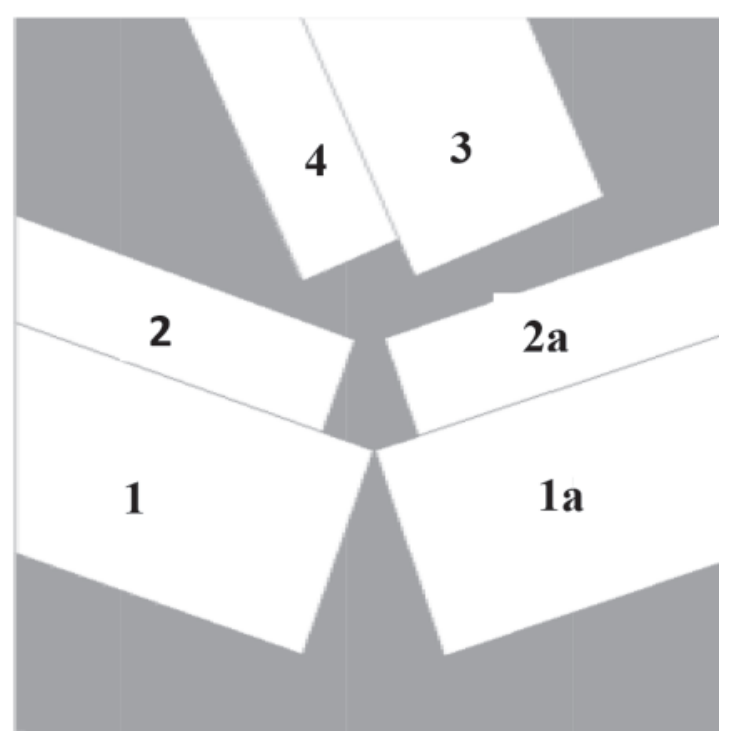

(c) Enlarged view of focus pillar

Fig.1 Typical layout of the depillaring panel by the fish-bone method 
pillar, as shown in the enlarged view of Fig.1c. The slicing operation is performed in two consecutive pillars simultaneously during the final extraction of the coal in this pattern. In each stage of slicing, the pillar's overall area reduces, leaving the irregular shape of ribs and snook, as shown in Fig.1b. Remnants are the remaining portion of the coal pillar during the slicing operation. The overlying strata' load above the slices redistributes to the pillar's intact portion during the final coal extraction. In-bye ribs are left in the goaf side against the slice to provide temporary support to the immediate roof during slicing operation. Ribs are designed to provide stable roof conditions during slicing and restrict the roof failure in the working area. The maximum load is carried by the snook while attempting the last slice from the working pillar. It is the closest natural support at the face against goaf. The strength of the snook controls the goaf encroachment and provides safe mining conditions. Hence, proper designing of the remnant is essential for safe mining in mechanized depillaring works. An optimum sized ribs/snook should be left during the slicing operation to restrict the goaf encroachment to the working area. A holistic approach by examining the strata, floor, panel design, extraction sequence, and remnant design can provide a safe depillaring operation. The paper's focus is to evaluate the remnant's stability, and hence, a literature survey has been conducted in this area.

\subsection{Design approaches proposed by researchers}

Depillaring operation commences with the extraction of the pillars in a sequential manner. In this process, the load of the overlying strata transfers to the goaf edge pillars. During the slicing operation, the remnant undergoes the residual phase, and hence, the abutment load shifts to the nearby intact pillars. The remnant may not provide the reaction to sustain the overlying strata's load and leads to the separation of the immediate strata from the primary strata. There may be a chance of immediate strata (overhang) failure after separation from the primary strata. At this stage, the overhang exerts a load on the remnants. If the strata weight (i.e., overhang) is more than the remnant's reaction, then pillar/remnant instability will arise, leading to the overriding situation. The ribs/snook left during final extraction plays a vital role in providing reaction to the overhang. Snook is the last natural support against the goaf in the pillar extraction sequence. Thus, its stability is an essential aspect of safe mechanized depillaring works.

Numerical simulation is a reliable technique for understanding the behaviour of the strata. Various researchers have attempted three-dimensional numerical simulations for accessing the induce stresses and roof behaviour in the depillaring panel (Jaiswal A et al., 2004; Kushwaha et al., 2010; Singh A K et al., 2011; Garg P et al. 2016; Ram S et al. 2017; Mandal P K et al. 2018). Some researchers have suggested the design concept based on the strata mechanics, as discussed in the above paragraph (Mark C, 2001; Singh R et al., 2016; Van-der-Merwe J N, 2005; Chawla S et al., 2017). Mark has suggested the load-bearing capacity of the stump (snook) using the Mark-Bieniawski stress function. It was also suggested to consider $40 \%$ of the stump's peak bearing capacity for further analysis. This exercise was conducted by taking various cases of US coalfields. It was further suggested that the final stump size should be in the range of $5-10 \%$ of the original coal pillar area. Singh R (2016) conducted a parametric study using numerical simulation techniques to assess snook stability with different roof characteristics and depth combinations. RMR has been used to categorize the immediate roof. An empirical relation for determining the stable size of the snook considering the depth of cover and RMR of the overlying strata has been suggested as given by Eq. (1):

$$
S=0.052 H^{0.74} R^{0.23} m^{2}
$$

Where $S$ is the effective size of the stable snook, $H$ is the depth of cover in $m$ and, $R$ is the CMRI-RMR.

Van-der-Merwe J N (2005) has suggested the design concept based on analytical solutions for designing the snook. He derives an expression for estimating the overhang's weight to befall and the snook's reaction. The author has also proposed a methodology to design the ribs and snook using numerical simulation techniques (Chawla et al., 2017). The design criteria consider the separation of immediate strata and induced tensile stress developed in the immediate strata. Suppose the remnant pillar is not providing a sufficient reaction to the immediate roof. In that case, the maximum tensile stress will be induced towards the remnant's out-bye side, which leads to overriding situations.

\subsection{Case study}

A case of bord and pillar panel has been chosen for the study.

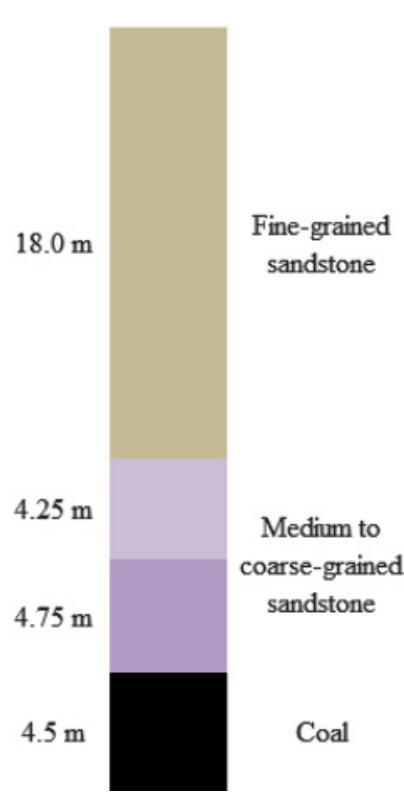

Fig.2 Borehole log The panel has a gradient of 1 in 9 and is situated at $200 \mathrm{~m}$ depth from the surface. The number of pillars in the panel is $30(5 \times 6)$, and the size of the pillars are $26 \mathrm{~m} \times 26 \mathrm{~m}$ (center to center). The width and height of the galleries were $5.5 \mathrm{~m}$ and $4.5 \mathrm{~m}$, respectively. Fig.2 shows the borehole log of the panel. Field investigation shows that the immediate roof failure generally occurs after the extraction of two pillars. The fish-bone pattern of pillar extraction has been adopted in the panel considering the size of the pillars. Fig.1a shows a typical depillaring 
phase considered for the study, i.e., after the extraction of two rows of pillars. The slicing angle was $110^{\circ}$, and Fig. 1c shows the slicing sequence.

Inbye rib of $5 \mathrm{~m}$ from the corner of the pillar was left before three consecutive slices having a cumulative width of $10 \mathrm{~m}$ and a length of $11 \mathrm{~m}$ during Stage I of the depillaring. The slice's cumulative width and length in Stage II are $10 \mathrm{~m}$ and 9 $\mathrm{m}$, respectively. The dimension of the slice and rib in Stage III is similar to Stage I. The final slice of cumulative width of $9 \mathrm{~m}$ and length of $5 \mathrm{~m}$ was taken out in Stage IV of depillaring, leaving a rib of $5 \mathrm{~m}$ from the corner of the pillar against the goaf. The final snook size is approximately $6 \mathrm{~m} \times 5 \mathrm{~m}$. Fig. $1 \mathrm{~b}$ shows the ribs/snooks' representative dimension for numerical simulations. Rock instrumentation such as auto warning tell-tale (AWTT), dual height tell-tale, rotary tell-tale, and stress cells were installed in the panel. AWTT has been installed in every original junction and the dip galleries (i.e., between slice 2 and slice $2 \mathrm{a}$ ), whereas rotary tell-tales in the level galleries (i.e., near slice 3 and slice 4).

\subsection{Numerical simulation}

Bord and pillar panel is a three-dimensional structure. Therefore, three-dimensional simulation has to be conducted for stability analysis. Numerical techniques are the most convenient way to determine the reaction of the remnant during the depillaring operation. The remnant should be designed to provide a necessary reaction to the overhang and prevent overriding situations. The remnant's FOS* concerning the weight of overhang should preferably in the range of 1.0-1.3. The higher FOS* of the remnant may delay the caving, whereas the FOS* less than one may create overriding situations. Thus, this range is considered as a design criterion.

The design of ribs/snook has been suggested based on the numerical simulation for a given case. The reaction by the remnant has been calculated for different slicing stages in the simulation. The FOS* has been computed as a ratio of the remnant's reaction and the overhang's weight. In general, the mine management keeps a record of the overhang area. As discussed, the overhanging weight is required for estimating the FOS*. Therefore, the probable overhang height is needed to be determined using the borehole log or rock instruments (tell-tale and borehole extensometer). Rock instrumentation proved to be a useful technique in determining the induced stress and the separation of overlying strata in coal mines (Smart B G D et al. 1978; YuZ et al. 1993; Singh R et al. 2004). If the remnant pillar does not provide a sufficient reaction, then the failure may occur up to the out-bye junction. Field investigation reveals that the overhang area in the panel during the depillaring operation was about twice the pillar size. The study considers an overhang area equivalent to the size of two and a half pillars for calculation purposes, as shown in Fig.3. A typical stage of depillaring just before the main fall

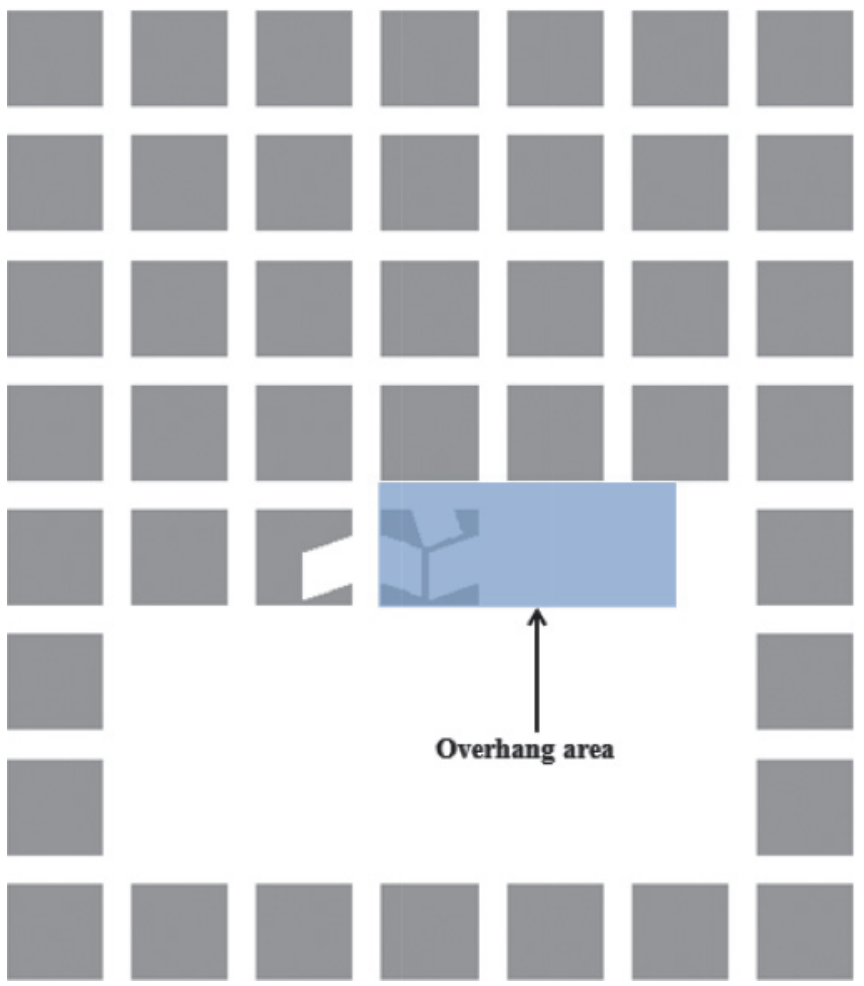

Fig.3 Typical depillaring panel showing area of the overhang

has been taken for simualation. Though, local falls of few meters in height had taken place in the goaf. However, the load of the main roof has still imposing it weight on the pillars. Thereofore, goaf has been considered as a void in the modlling.

A model has been prepared using FLAC3D (Itasca 2000), which works on the finite difference method. The model has been constructed using brick elements. Fig.4 shows the discretized view of the model. The pillar under consideration is constructed so that the slices can be taken out at each stage of depillaring. An interface has been introduced between the immediate roof and the main roof in the model. As per the

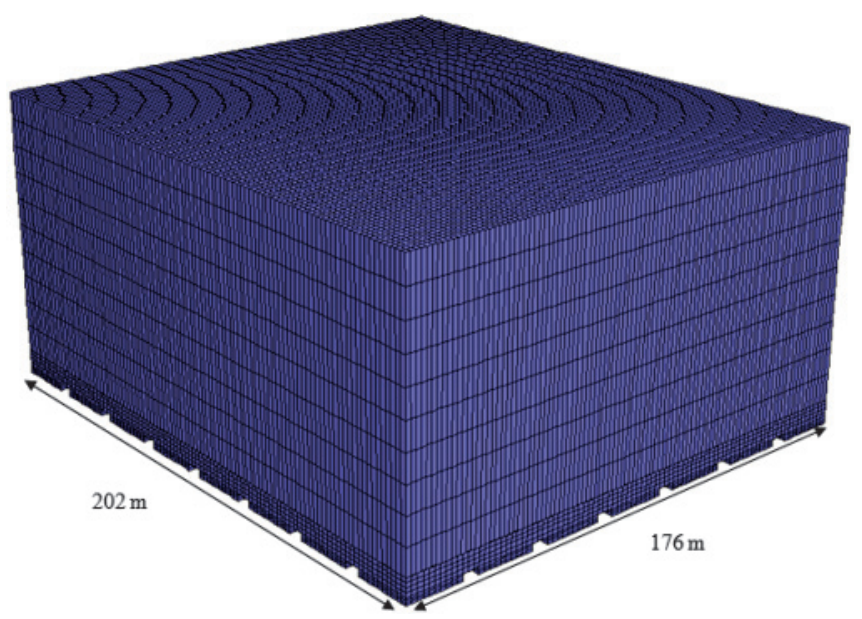

Fig.4 Discretized view of the model (three-dimensional) 
borehole section, the separation may arise either within 4.75 $\mathrm{m}$ or at a level of $9 \mathrm{~m}$. Therefore, two different scenarios have been analyzed considering the immediate roof thickness as $4.75 \mathrm{~m}$ (i.e., Scenario I) and $9 \mathrm{~m}$ (i.e., Scenario II).

Coal is a strain-softening material. Therefore, appropriate material properties have to be assigned. Some researchers consider coal as Hoek-Brown material (Islavath SR, 2019; Jaiswal et al., 2009; Medhurst TP et al., 1998), and some consider Mohr-Coulomb material (Kumar A et al., 2017; Murali M G et al., 2001). In the present analysis, the coal has been considered as a Mohr-Coulomb material. The strength parameters i.e. cohesion and friction angle for coal have been determined using hit and trial approach by simulating a single coal pillar as a separate analysis until the numerical pillar strength becomes equivalent to the pillar strength proposed by Sheorey (1987). In this analysis dilation angle has been considered as zero. Table 1 shows the strength parameters used in the model for the coal. The main roof fall has not occurred in the panel for the selected depillaring stage. Hence, considering the software's computational time, the roof has been considered elastic, having a density, Young's modulus, and Poisson's ratio equal to $2500 \mathrm{~kg} / \mathrm{m}^{3}, 5 \mathrm{GPa}$, and 0.2 , respectively.

\begin{tabular}{cccc}
\multicolumn{4}{c}{ TABle 1: Strength PARAMETERS USED IN THE MODEL FOR COAL } \\
$\begin{array}{c}\text { Plastic } \\
\text { strain }\end{array}$ & $\begin{array}{c}\text { Cohesion } \\
(\mathrm{MPa})\end{array}$ & $\begin{array}{c}\text { Friction } \\
\text { angle }\left({ }^{\circ}\right)\end{array}$ & $\begin{array}{c}\text { Dilation } \\
\text { angle }\left({ }^{\circ}\right)\end{array}$ \\
0 & 1.75 & 30 & 0.0 \\
0.05 & 0.5 & 17 & 0.0 \\
\hline
\end{tabular}

The vertical stress $\left(\sigma_{v}\right)$ and the horizontal stress $\left(\sigma_{h}\right)$ have been initialized in the model, as given in Eq. (2) and Eq. (3) (Sheorey, 1994).

$$
\begin{aligned}
& \sigma_{v}=0.025 H \\
& \sigma_{h}=2.4+0.01 H(M P a)
\end{aligned}
$$

where, $H$ is the depth of cover in $m$

The model has been constructed up to the surface level; hence, no additional load was applied to the model. The model sides were restricted in lateral directions and the bottom in the downward direction. The model has been simulated sequentially for four different stages of depillaring (namely Stage I through Stage IV) to replicate the depillaring operation.

\subsection{Results and discussion}

The simulation results have been plotted in terms of vertical stress and yielding at the seam's middle level, as shown in Fig.5. Fig.5a depicts that the pillar near the goaf experiences more stress than the far end pillars. The focused pillar shows peak vertical stress of about $23 \mathrm{MPa}$ before the slicing operation. The influence of the goaf is observed up to one pillar ahead of the goaf edge. The focused pillar yields about $60 \%$, as seen in Fig.5a. The pillar sides nearby the goaf yields about $4 \mathrm{~m}$ from the sides, while pillars away from the goaf experience the symmetrical stress distribution pattern and yield about $2 \mathrm{~m}$ from the sides. Therefore, the peak load is slightly shifted towards the core.

Fig.5b shows the panel's simulation results at different depillaring stages (i.e., Stage I through Stage IV). It has been observed from the simulation results that the peak stress (i.e., approximately $25 \mathrm{MPa}$ ) is shifted towards the center of the remnant pillar in stage I. In-bye rib experiences the stress of about $2 \mathrm{MPa}$ during this stage, and the remnant yields ultimately. The reaction provided by the remnant has been obtained using the codes of FLAC3D. The reaction provided by the remnant in Stage I is 1756.0 MN. The peak stress is shifted to the pillar next to the focused pillar in Stage II. The remnant shows maximum stress of about $10 \mathrm{MPa}$ in Stage II, and the reaction provided is $782.0 \mathrm{MN}$. The immediate intact pillar yields completely in stage III. The remnant shows a stress value of about $6 \mathrm{MPa}$ in Stage III and provides a reaction of about 782.0 $\mathrm{MN}$. The reaction provided by the remnant reduces gradually during the slicing operation and reduces to $367.8 \mathrm{MN}$ in Stage IV. The snook shows maximum stress of about $5 \mathrm{MPa}$ in this Stage IV. A slight influence of the slicing operation was seen on the pillar nearby working pillars.

It is to be noted that the remnant is failed/yielded during the depillaring operation due to excessive induced stress. However, it is provided the reaction to the immediate roof so that it will hold the immediate roof during slicing operation. The FOS* of the remnant has been taken as a key parameter for stability analysis of the remnant during the depillaring operation. It has been estimated as a ratio of residual strength of remnant and weight of the immediate roof. Two different scenarios have been considered to evaluate the FOS* of the remnant, considering the bed separation at the height of 4.75 $\mathrm{m}$ and $9 \mathrm{~m}$ from the roofline. The overhang density has been taken as $2.5 \mathrm{~T} / \mathrm{m}^{3}$, and its area to be $1690 \mathrm{~m}^{2}$ (Fig.3). The reaction given by the remnant pillar has been obtained at each depillaring stage using the simulation results, while the weight of the overhang is calculated by using Eq.4.

\section{Weight of overhang $=$ \\ (Volume of the overhang) $X$ (density)}

The overhang's weight in Scenario I and II are calculated as 196.67 $\mathrm{MN}$ and 372.65 MN, respectively. The remnant's FOS* in different depillaring stages for overhang thickness of $4.75 \mathrm{~m}$ and $9 \mathrm{~m}$ has been calculated and shown in Table 2 .

\begin{tabular}{|c|c|c|c|c|c|}
\hline \multirow[t]{2}{*}{ Stage } & \multirow{2}{*}{$\begin{array}{l}\text { Load } \\
(\mathrm{MN})\end{array}$} & \multicolumn{2}{|c|}{ Wt. of overhang (MN) } & \multicolumn{2}{|c|}{ FOS* } \\
\hline & & Scenario I & Scenario II & Scenario I & Scenario II \\
\hline I & 1756.00 & 196.67 & 372.65 & 8.9 & 4.7 \\
\hline II & 782.00 & 196.67 & 372.65 & 4.0 & 2.1 \\
\hline III & 782.00 & 196.67 & 372.65 & 4.0 & 2.1 \\
\hline IV & 367.80 & 196.67 & 372.65 & 1.9 & 1.0 \\
\hline
\end{tabular}

TABLE 2: The FACTOR OF SAFETy (FOS*) OF THE REMNANT PILLAR 


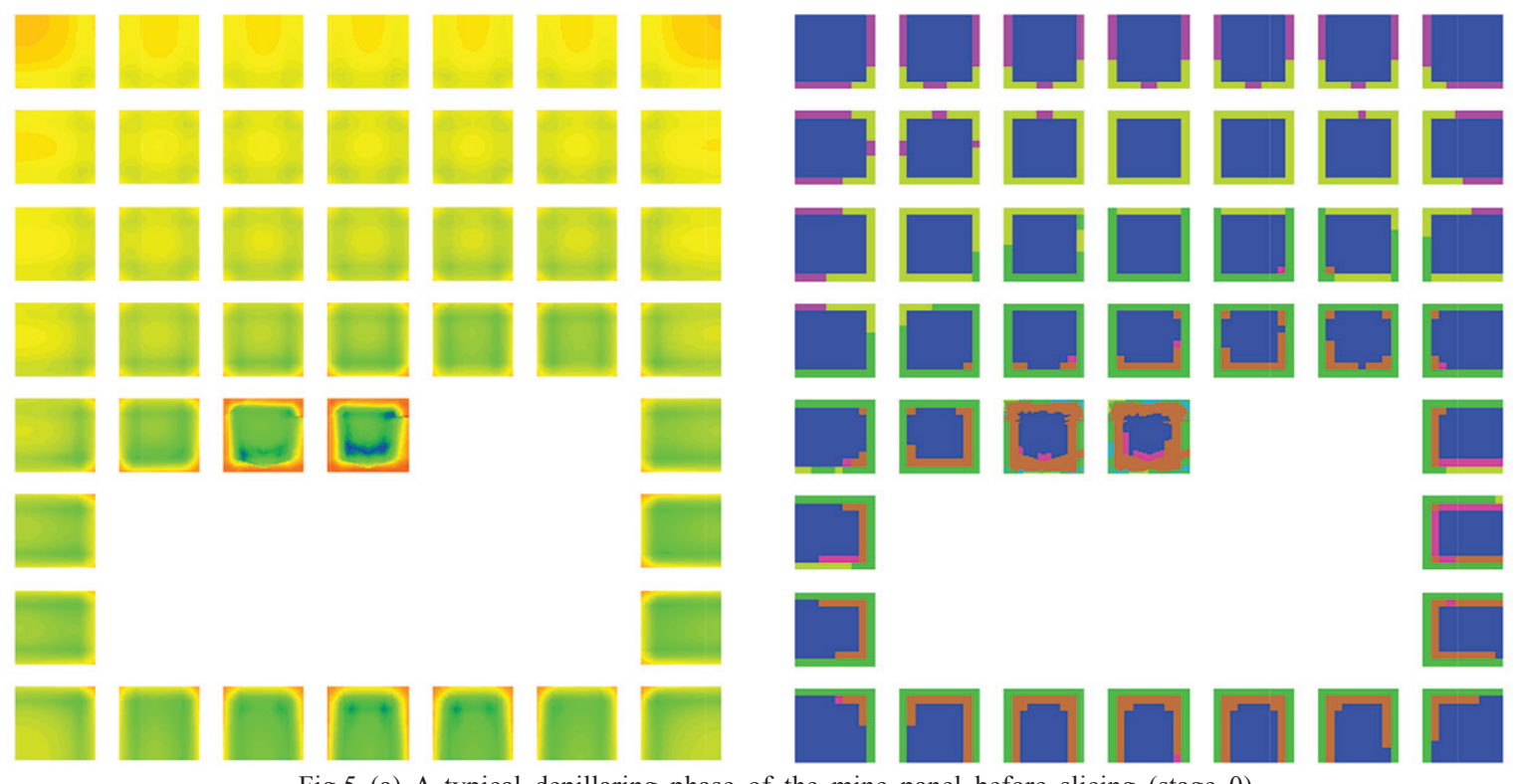

Fig.5 (a) A typical depillaring phase of the mine panel before slicing (stage 0)
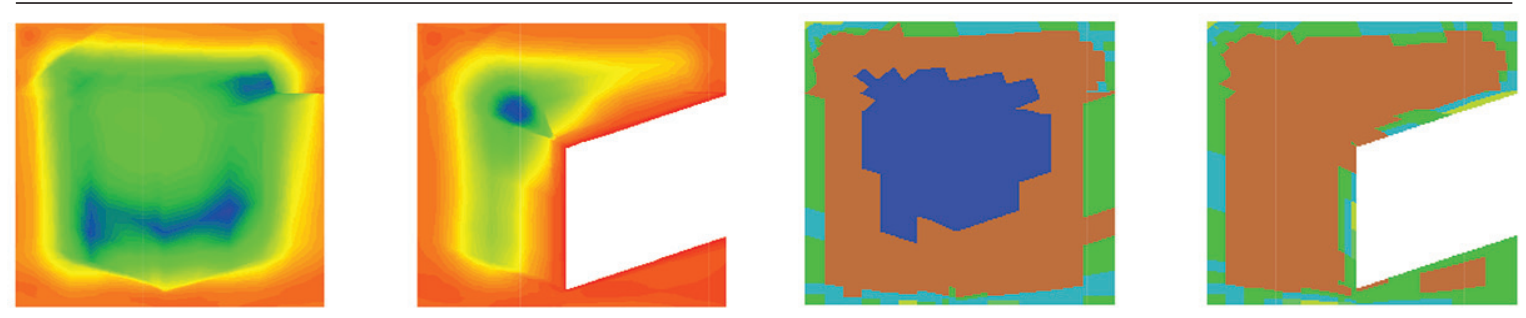

Stage I
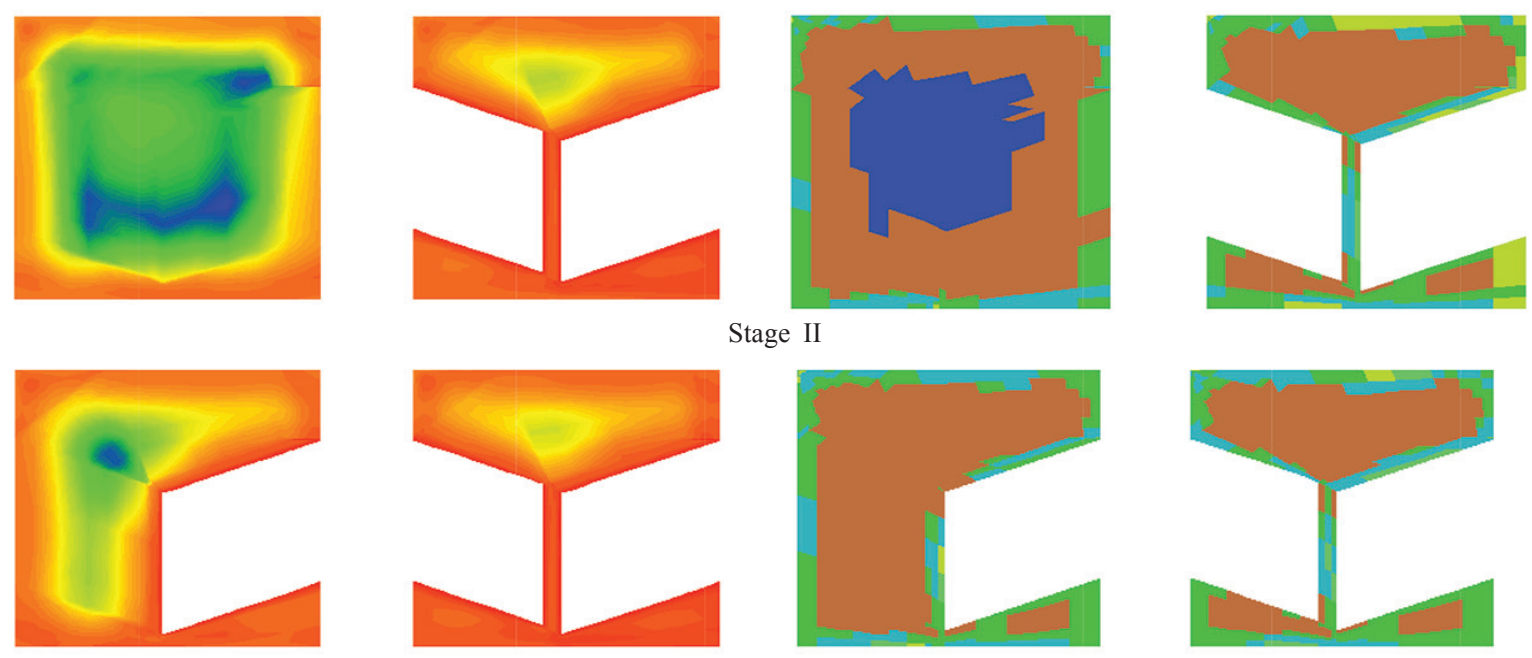

Stage II
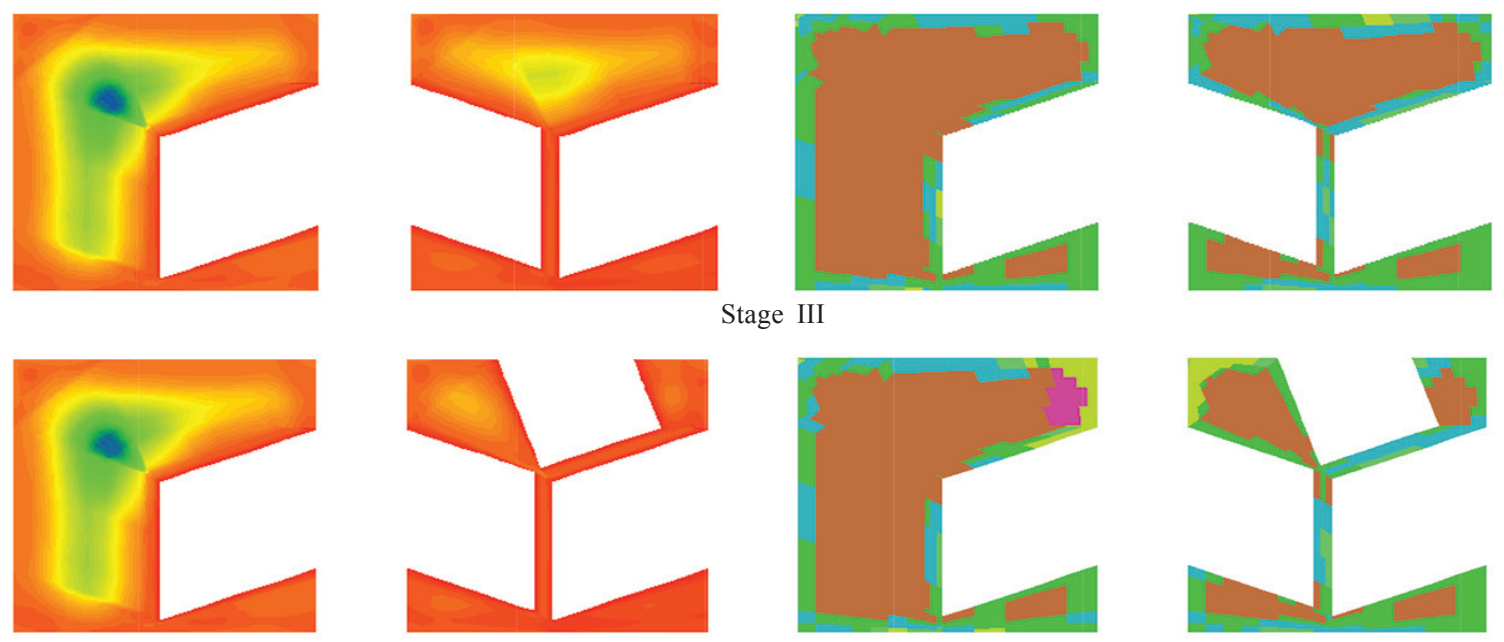

Stage III

Fig.5 (b) Typical layout of the focused pillar during the slicing operation

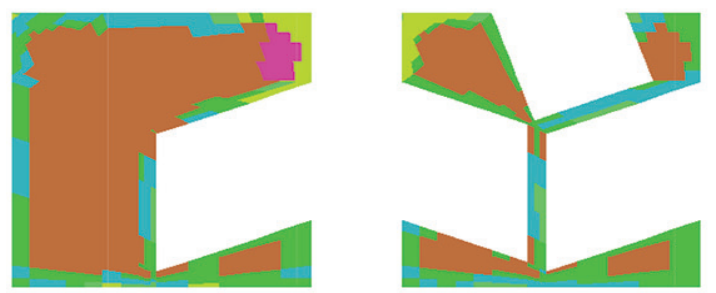

Stage IV

(continued on next page) 


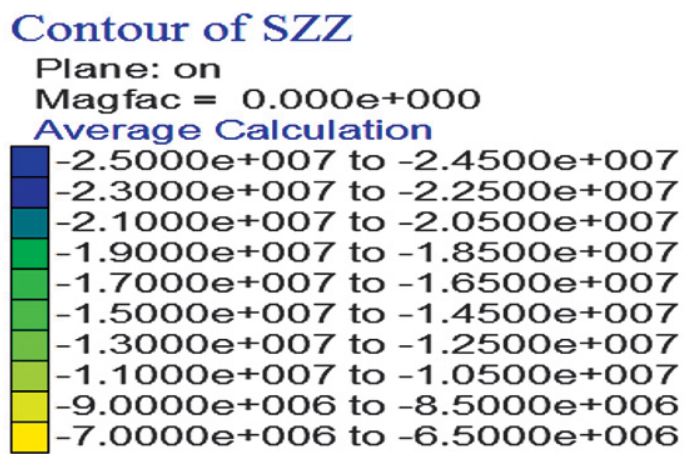

\author{
None \\ shear-n shear-p \\ shear-n shear-p tension-p \\ shear-n tension-n shear-p tension-p \\ shear-p \\ shear-p tension-p \\ tension-n shear-p tension-p
}

Fig.5 Vertical stress profile (left) and yield profile (right) at the middle level of the seam

One has to observe the borehole log and the instrumentation results to identify the roof separation's probable location. In this section, a numerical simulation scheme has been highlighted for a typical case for designing the depillaring scheme. The remnant's FOS* is 1.9 and 1.0 at stage IV for Scenario I and II, respectively.

Instrumentation results and the snook's status have to be considered while taking the pillar's final slice for Scenario II. The galleries/junctions' width has increased to $8 \mathrm{~m}-10 \mathrm{~m}$ due to the pillars' yielding from the sides. The pillar surrounding the goaf yields about $6 \mathrm{~m}$ from the corners during depillaring Stage III and IV. Keeping this fact in mind, one has to design the roof support properly.

Based on numerical simulation results, a graph is plotted (Fig.6) in between the reaction provided by the remnant visà-vis its area. The graph shows an exponential relationship, as expressed in Eq.5. The R2 value of the equation is 0.98 . One can design the remnant pillar using Eq.4 and Eq.5.

$\mathrm{L}=73.31 X \exp ^{(A / 100)}$

Where $L$ is Load on the remnant pillar in $\mathrm{MN}$, $A$ is the area of the remnant pillar in $\mathrm{m}^{2}$

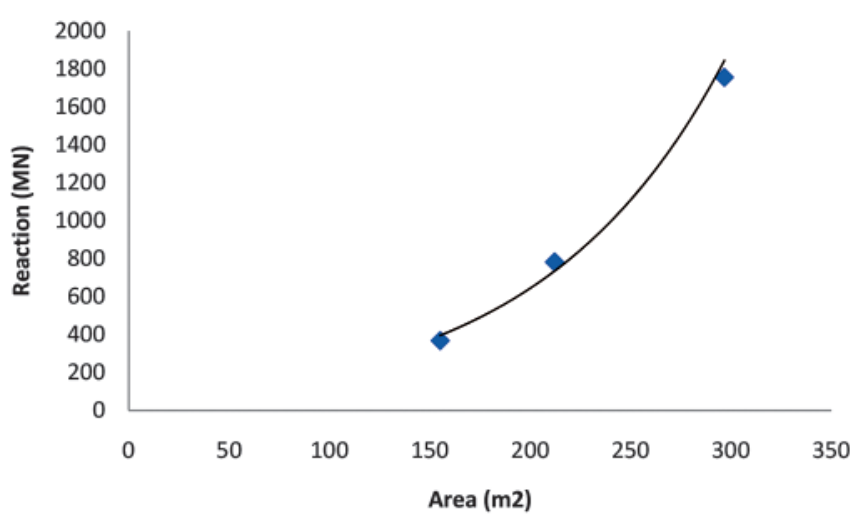

Fig.6 Reaction provided by the remnant pillar vis-à-vis its area

\subsection{Conclusion}

A numerical simulation scheme has been proposed in the study to determine the FOS of the remnant during depillaring operation. A bord and pillar panel having a pillar size of $26 \mathrm{~m}$ $\times 26 \mathrm{~m}$ at a depth of $200 \mathrm{~m}$ has been considered for the simulations. The simulation result shows about $60 \%$ yielding of the focused pillar before the slicing operation. The remnant yields ultimately as the slicing operation begins. Peak stress of about $25 \mathrm{MPa}$ has been observed in the remnant during Stage I. The peak stress shifted to the nearby pillar in the upcoming stages of slicing operation. The reaction provided by the remnant was found to be $1756 \mathrm{MN}$ in Stage I, which goes on decreasing with the further slicing operation, and was found to be $367.8 \mathrm{MN}$ in Stage IV. The load-bearing capacity of the remnant shows an exponential relationship with its area. Numerical simulation alone cannot give desired results; therefore, field instrumentation should also be clubbed with numerical simulation to determine the pillars/ remnants' stress conditions and dilation of the strata. The identification of the separation of the immediate strata is of utmost importance. The FOS* of the remnant after each slice is calculated using Eq.4 and 5. In general, the remnant's FOS* should be in the range of 1.0-1.3 for safe mine workings. Slicing operation must be restricted if the FOS* of the remnant reduces below 1.0. One can identify the separation of the overhanging strata using rock instrumentation, borehole log, or past experiences and design the remnant accordingly.

\section{References}

1. Chawla S, Jaiswal A, Shrivastva B K (2017): Design of snook in the depillaring panel using continuous miner. Journal of the Institution of Engineers (India) Series: D. 99(1):39-49.

2. Garg P, Jaiswal A (2016): Estimation of the modulus of the caved rock for underground coal mines by back analysis using numerical modelling. Journal of the Institution of Engineers (India) Series: D97(2):269-273.

3. Islavath SR (2019): Stability of Continuous Miner Workings using Numerical Modelling Approach. Journal of Mines and Metals Fuels. 67(8):360-365.

4. Itasca (2000): FLAC (Fast Lagrangian Analysis of Continua). Itasca Consulting Group Inc.Minneapolis Minnesota 55401 USA Version 3.0.

5. Jaiswal A, Sharma S K, Srivastava B K (2004): Numerical modeling study of asymmetry in the induced stresses over coal mine pillars with the advancement of the goaf line. International Journal of Rock Mechanics and Mining Sciences 41:859-864. 
6. Jaiswal A, Srivastava B K (2009): Numerical simulation of coal pillar strength. International Journal of Rock Mechanics and Mining Sciences 46:779-78

7. Kushwaha A, Singh S K, Tewari S, Sinha A (2010): Empirical approach for designing of support system in mechanized coal pillar mining. International Journal of Rock Mechanics and Mining Sciences 47(7):1063-1078.

8. Mandal P K, Das A J, Kumar N, Bhattacharjee R, Tewari S, Kushwaha A (2018): Assessment of roof convergence during driving roadways in underground coal mines by the continuous miner. International Journal of Rock Mechanics and Mining Sciences 108:169-178.

9. Mandal P K, Singh A K, Ram S, Singh A K, Kumar N, and Singh R (2004): Strata behavior investigation of India's first depillaring face with continuous miner and shuttle car. Minetech 25(6):3-12.

10. Mark C, Zelanko J C (2001) Sizing of final stumps for safer pillar extraction. In: Proceeding of 20th International Conference on Ground Control in Mining. Morgantown WV USA, pp. 59-66.

11. Medhurst T P, Brown E T(1998): A study of the mechanical behaviour of coal for pillar design. International Journal of Rock Mechanics and Mining Sciences and Geomechanics Abstracts 35:1087-105.

12. Murali Mohan G, Sheorey P R, Kushwaha A (2001): Numerical estimation of pillar strength in coal mines. International Journal of Rock Mechanics and Mining Sciences 38:1185-92.

13. Ram S, Kumar D, Singh A K, Kumar A, Singh R (2017): Field and numerical modelling studies for efficient placement of roof bolts as breaker line support. International Journal of Rock Mechanics and Mining Sciences 93:152-162.

14. Sheorey PR, Das MN, Barat D, Prasad RK, Singh B (1987): Coal pillar strength estimation from failed and stable cases. International Journal of Rock Mechanics and Mining Sciences \& Geomechanics Abstracts 24(6):347-355.

15. Sheorey P R (1994): A theory for in situ stresses in isotropic and transversely isotropic rock. International journal of rock mechanics and mining sciences and geomechanics abstracts 31: 23-34.

16. Singh A K, Singh R, Maiti J, Kumar R, and Mandal P K (2011): Assessment of mining-induced stress development over coal pillars during depillaring. International Journal of Rock Mechanics and Mining Sciences 48:805-818.

17. Singh R, Singh A K, Coggan J, Ram S (2016): Rib/snook design in mechanized depillaring of rectangular/square pillars. International Journal of Rock Mechanics and Mining Sciences 84:119-129.

18. Singh R, Singh A K, Maiti J, Mandal P K, Singh R, and Kumar R (2011): An observational approach for assessment of dynamic loading during underground coal pillar extraction. International Journal of Rock Mechanics and Mining Sciences 48:798-804.

19. Singh R, Singh A K, Mandal P K, Singh M K, and Sinha A (2004): Instrumentation and monitoring of strata movement during underground mining of coal. Minetech 25(5):12-26.

20. Singh S K, Agrawal H, Singh, Awanindra P (2017): Rib stability: A way forward for safe coal extraction in India. International Journal of Mining Science and Technology 27(6): 1087-1091.

21. Smart B G D, Singh R N, Issac A K (1978): A borehole instrumentation system for monitoring strata displacement in three dimensions. International Journal of Rock Mechanics and Mining Sciences and Geomechanics Abstracts 15(2): 77-85.

22. Van-der-Merwe J N (2005): Fundamental analysis of the interaction between overburden behaviour and snook stability in coal mines. Journal of the Southern African Institute of Mining and Metallurgy 105(1):63-73.

23. Yu Z., Chugh Y. P., Miller P. E., Yang G. (1993): A study of ground behavior in longwall mining through field instrumentation. International Journal of Rock Mechanics and Mining Sciences and Geomechanics Abstracts 30(7):1441-1444.

\section{SUSTAINABLE GROWTH OF INDIAN COAL INDUSTRY: POLICY PERSPECTIVES AND RECOMMENDATIONS}

\section{(Continued from page 44)}

39. UNDP and UN Environment (2018): Managing mining for sustainable development: A sourcebook. Bangkok: United Nations Development Programme

40. Upgupta S, Singh P. K. Impacts of Coal mining: a Review of Methods and Parameters Used in India. Curr World Environ 2017;12(1). DOI:http://dx.doi.org/10.12944/ CWE.12.1.17

41. Vrkljan, Darko and Klanfar, Mario and Tost, Michael and Endl, Andreas. (2017): MIN-GUIDE Version Innovative Exploration and Extraction Deliverable 3.4. Guidelines and recommendations for future policy and legislation Minerals Policy Guidance for Europe MIN-GUIDE -D 3.4. Guidelines and recommendations for future policy and legislation. 10.13140/RG.2.2.23128.65289.
42. Woods, Bryndis and Schlissel, David (2019): "Risks Growing for India's Coal Sector", IEEFA (Institute for Energy Economics and Financial Planning) Available on https://ieefa.org/wp-content/uploads/2019/08/RisksGrowing-for-India-Coal-Sector_September-2019.pdf

43. Yu, B., Tai, Y., Gao, R., Yao, Q., Li, Z., \& Xia, H. (2020): The sustainable development of coal mines by new cutting roof technology. Royal Society open science, 7(6), 191913. https://doi.org/10.1098/rsos.191913

44. Zhou, C., Damiano, N., Whisner, B., \& Reyes, M. (2017). Industrial Internet of Things: (IIoT) applications in underground coal mines. Mining engineering, 69(12), 5056. https://doi.org/10.19150/me.7919 